\title{
LUPUS LIKE SYNDROME FOLLOWING PARVOVIRUS B19 INFECTION
}

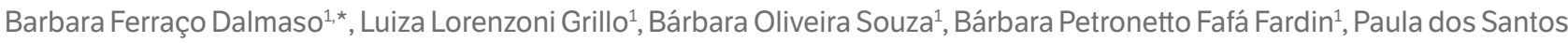
Athayde ${ }^{1}$, Mariana de Oliveira Macabú ${ }^{1}$, João Peçanha Schwartz ${ }^{1}$, Fernanda Sales Soares de Oliveira' ${ }^{1}$, Tiago Barcelos da Silva ${ }^{1}$, Guilherme Vallin Garcia ${ }^{1}$, Laura Gonçalves Aguiarr ${ }^{1}$, Heitor Filipe Surlo ${ }^{1}$, Laís Pizzol Pasti ${ }^{1}$, Hellen Carvalho Ribeiro ${ }^{1}$, João Victor Cornachini ${ }^{1}$, Anna Carolina Simões Moulin ${ }^{1}$, Ketty Lysie Libardi Lira Machado ${ }^{1}$, Érica Vieira Serrano ${ }^{1}$, Raiza Cansian Tuão ${ }^{1}$, Débora Marques Veghini ${ }^{1}$, Gustavo Pinto de Oliveira Gomes ${ }^{1}$, Weider Andrade Tomé1 ${ }^{1}$, Luiza Vallory Alochio ${ }^{1}$, Luiza Correa Rodrigues Dalpiero ${ }^{1}$, Ana Paula Espindula Gianordoli¹, Lídia Balarini da Silva ${ }^{1}$, Matheus Pereira Rosi ${ }^{1}$, Valéria Valim ${ }^{1}$
\end{abstract}

1.Universidade Federal do Espírito Santo, Vitória (ES), Brazil.

*Corresponding author: babi_dalmaso@hotmail.com

\section{BACKGROUND}

Human parvovirus B19 (HPV-B19) is a single-stranded DNA virus that has affinity mainly for erythroblasts in the bone marrow. Infection with HPV-B19 can trigger a symptomatic transient autoimmune state, especially in females. This virus has been associated with the onset, exacerbation and mimicking of systemic lupus erythematosus (SLE), presenting a similar clinical picture, such as fever, rash, symmetric arthralgia and photosensitivity. In this case report we present a case of parvovirus B19 infection with lupuslike symptomatology.

\section{CASE REPORT}

A 29-year-old female patient started in May 2019 presenting with left retro-ocular headache, lasting $24 \mathrm{~h}$ and photophobia; with improvement after use of analgesic. After 3 days, she evolved with edema (Figure 1), pruritus, and hyperemia of left upper and lower limbs. She progressed with arthritis in the proximal interphalangeal and metacarpophalangeal joints, with morning stiffness lasting more than $1 \mathrm{~h}$ and arthralgia in the feet bilaterally, as well as the emergence of painful anterior cervical and occipital lymphadenomegaly. The patient evolved with an intermittent malar rash and upper limbs rash, which worsened when exposed to sunlight. The patient sought health care and on physical examination, Raynaud's phenomenon and malar rash were observed (Figure 2). Laboratory tests were requested, which included viral serology for Hepatitis B and C, HIV, syphilis, and Epstein-Barr; sputum BAAR and serology for chikungunya, CMV, toxoplasmosis, zika virus, dengue, and rubella, which were all negative. Serology for HPV-B19 was also performed, with positive IgM and $\mathrm{lgG}$, and parvovirus infection was confirmed. Autoimmune markers were requested: PCR $5.3 \mathrm{mg} / \mathrm{dL}, \mathrm{ESR} 25 \mathrm{~mm} / 1 \mathrm{~h}$, negatives ANA, FR, anti-Ro and anti-La. Patient underwent ultrasonography (USG) of hands and complete abdominal, without significant changes; and transthoracic echocardiogram, showing mild pericarditis. In view of the presenting clinical picture, the case was considered a

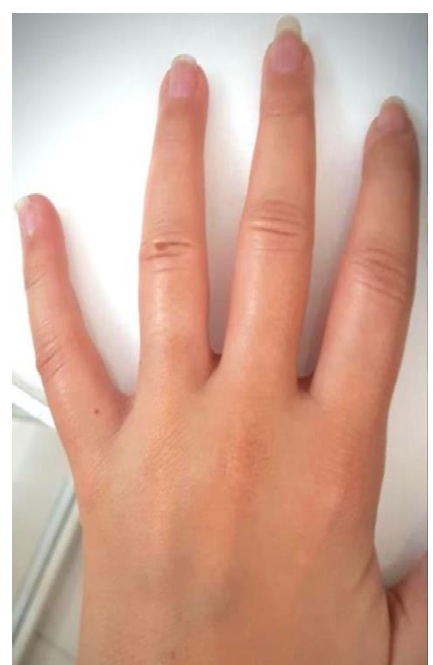

Figure 1. Edema in left hand.

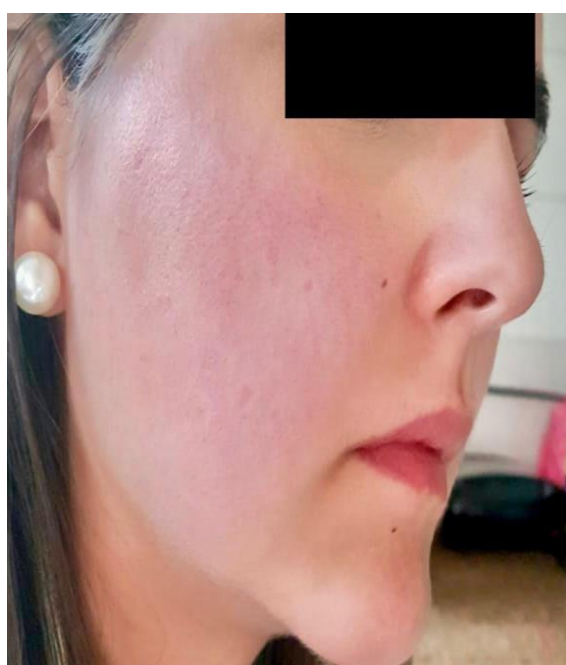

Figure 2. Malar rash.

Realização: 
lupus-like syndrome associated with parvovirus B19. Hydroxychloroquine $400 \mathrm{mg} /$ day was prescribed for 3 months to control the joint condition, being suspended with sustained improvement.

\section{CONCLUSION}

HPV-B19 infection is an asymptomatic disease in most cases and self-limited, but more rarely, clinical presentations may mimic or trigger autoimmune rheumatologic diseases, including SLE. In this report we see a patient who initiated symptoms of malar rash and arthritis of the hands and arthralgia in the feet, with onset of cervical lymphadenopathy, photosensitivity, pericarditis and anemia, with positive serology for HPV-B19. Therefore, it is noted a lupus-like syndrome initiated after parvovirus.

\section{KEYWORDS}

Lupus like syndrome, Parvovirus B19, Systemic lupus erythematosus. 